\title{
Institucionalismo informal: tras las huellas de un discurso institucionalista informal
}

\section{Carlos Alberto Navarrete Ulloa*}

Perfiles Latinoamericanos, 24(47)

2016 | pp. 283-306

DOI: $10.18504 / \mathrm{pl} 2447-003-2016$

\section{Resumen}

El nuevo institucionalismo representó el retorno de las instituciones al centro de la teoría social y política. Sin embargo, aun cuando se enfatiza en la importancia de las reglas informales, las formulaciones teóricas sobre las mismas continúan como asignatura pendiente. En este trabajo se rastrean los rasgos de un posible texto institucionalista informal a partir de la investigación teórica, con el objetivo de identificar los componentes articuladores de un discurso institucional informal.

\begin{abstract}
The new institutionalism represented the return of the institutions at the center of social and political theory. However, even when it emphasizes the importance of informal rules, theoretical formulations about them continue as pending. It tracks for traces of a possible informal institutionalist discourse from theoretical research. The aim is to identify the components articulators of informal institutional discourse.
\end{abstract}

Palabras clave: instituciones informales, proceso político, reglas del juego, hábitos, investigación teórica, significaciones.

Keywords: informal institutions, political process, rules, habits, theoretical research, significations.

* Doctor en Ciencias Sociales por El Colegio de Jalisco. Profesor investigador, Centro Universitario de Tonalá de la Universidad de Guadalajara. 
n este trabajo se intenta articular un discurso institucionalista informal a partir de la investigación teórica. Desde la aparición del influyente trabajo de March y Olson (1984), en el que declararon el surgimiento de un nuevo institucionalismo, se reconocen importantes avances en la investigación dentro de este enfoque de análisis de la sociedad y de las reglas que moldean el comportamiento de los agentes (Helmke \& Levitsky, 2004: p. 734). No obstante, March y Olson destacaban entre las perspectivas institucionalistas a la política como interpretación de la vida, subrayando el papel de los símbolos como instrumentos de orden interpretativo, y al proceso político como más importante que la decisión o los resultados. De manera que, para estos pensadores, entre las asignaturas pendientes resaltaban la ausencia de formulaciones teóricas acerca de la importancia de los símbolos, el ritual, la ceremonia, el mito.

En toda definición de institución está invariablemente implícita la preexistencia de la institucionalidad informal, sin embargo, predomina en la literatura la atención a la institucionalidad formal. Por lo demás, la literatura del nuevo institucionalismo refiere siempre a la importancia de atender de modo complementario las reglas formales e informales, pero la reflexión sobre estas últimas se ha mantenido sin contribuciones determinantes, salvo obras seminales sobre la materia. ${ }^{1}$ No obstante, existe una rica y dispersa bibliografía que atiende diversos aspectos de las instituciones informales como son el clientelismo, el faccionalismo y el patronazgo, además de la cuestión sobre caciques y caudillos.

En tal tesitura, el objetivo aquí es la reconstrucción conceptual de la categoría institución informal mediante la investigación teórica para proponer los componentes de un posible discurso institucionalista informal. Asumimos que la parte informal de las instituciones es importante para la calidad de la democracia y sugerimos que en la literatura existente no se han precisado sistemáticamente los componentes ni los referentes a los que aplica la categoría institución informal. Por tanto, buscamos el argumento subyacente presente en la literatura sobre las instituciones informales; por su relativa dispersión, sólo realizamos una primera aproximación, aun cuando el artículo es parte de una amplia investigación empírica que busca la institucionalidad informal en partidos políticos y en la acción de las élites parlamentarias a nivel subnacional en México.

El artículo se estructura en tres secciones. En la primera se presenta en términos generales el marco de la reflexión sobre las instituciones formales e informales. En la segunda se buscará la integración de la literatura que desde distintas

1 Las obras que abordan explícitamente el tema son recientes: Benton (2007), Freidenberg \& Levitsky (2007), Helmke \& Levitsky (2004, 2006), Leiras (2004), exceptuando el provocador trabajo de O’Donnell (1996). 
perspectivas reflexiona en torno a cuestiones de institucionalidad informal. Al final se bosquejan los componentes probables de la institucionalidad informal.

\section{Instituciones e informalidad: una contextualización del institucionalismo informal}

Las instituciones son las reglas que establecen límites a la interacción humana. Las limitaciones pueden ser de carácter formal o informal (North, 1993), las primeras son codificadas explícitamente, facilitando la comprensión y el cumplimiento de expectativas en sociedades complejas. Las reglas formales son definidas y garantizada su aplicación por organismos especializados como congresos y tribunales. En contraste, en las reglas informales la garantía de su aplicación es por sanción social, ya que son tácitas y significadas por relaciones simbólicas, rituales y tradiciones.

Para Douglass North, las limitaciones informales son acuerdos que resuelven problemas de coordinación, en los que el intercambio es autorreforzado, lo que disminuye los costos de la mediación (North, 1993: p. 60). North habla indistintamente de limitaciones informales, cultura, convicciones, códigos de conducta autoimpuestos, preferencias-percepciones subjetivas, actitudes mentales subjetivas. No obstante, también ofrece una precisión: las limitaciones informales "provienen de información trasmitida socialmente y son parte de la herencia que llamamos cultura" (North, 1993: p. 55).

En otra perspectiva, se entiende por institución a pautas regularizadas de interacción que crean expectativas de continuidad conforme a reglas sancionadas y sostenidas por ella (O’Donnell, 1996). Complementariamente, se dice que las instituciones son "sistemas de reglas sociales establecidas y habituales que estructuran las interacciones sociales” (Hodgson, 2006: p. 2). Aun cuando las instituciones formales estructuran el proceso político, este mismo es generador de restricciones y oportunidades, es el ámbito institucional informal que impacta en la calidad de las instituciones. En suma, las instituciones informales evolucionan, complementando o sustituyendo a las reglas formales, en relaciones que pueden ser positivas o negativas (Prats, 2008).

El nuevo institucionalismo establece el centro de atención en las instituciones, tanto formales como informales: normas, recursos o símbolos institucionales, procesos de políticas, códigos, cultura y comunicación orientan el comportamiento de los actores (Mariscal, 2003: p. 36). Decir que las instituciones importan implica que la lucha política es mediada por arreglos institucionales que influyen en el sentido del cambio. Las instituciones cuentan porque estructuran el juego: determinan quién y cómo accede al proceso político, cuáles son 
las rutas de acción aceptadas y qué comportamientos son esperados, aceptados y/o compartidos.

A partir de los años noventa se ha destacado el papel de las instituciones para el desarrollo, ${ }^{2}$ y recientemente el enfoque de la gobernanza se ha interesado en las relaciones de codependencia tejidas entre redes sociales, económicas y políticas o de gobierno (Aguilar, 2013, 2014). En tal lógica, el nuevo institucionalismo histórico $(\mathrm{NIH})$ permite comprender cómo las características institucionales impactan sobre la capacidad de gobernanza y estructuran el proceso político. El NIH plantea que el proceso de institucionalización no es neutro, ya que poderosos actores buscan las reglas que más favorecen su juego. Es importante comprender que el juego se realiza en el campo de dos significativas influencias, que inciden en sentidos contrarios:

1) El formal. Implica que el juego es entre una pluralidad de poderes, y aun definidas las reglas en determinado sentido, no es automático el control de tales reglas ni su utilización al servicio de los fundadores (Mariscal, 2003: p. 320).

2) El informal. Los actores poderosos no sólo inciden en el sentido de la formación de reglas favorables, sino que pueden actuar efectivamente en sentidos diversos a los permitidos por las reglas positivas.

El NIH supone que el momento originario de una institución tiende a preservar y estructurar la subsecuente formulación de políticas (Johansson \& Raunio, 2005: p. 518). El origen incide en el destino: las acciones iniciales empujan el comportamiento individual por senderos que es difícil revertir. En un mundo complejo el intercambio es interpersonal, esto implica información limitada sobre el interlocutor y escasa sobre otros actores sociales, en consecuencia, el rumbo de las acciones es incierto y los acuerdos son de difícil negociación y renegociación. La negociación nunca termina, los actores ajustan sus acciones necesariamente al cambio continuo de las circunstancias. ${ }^{3}$ Este contexto explica la emergencia de las instituciones como marcos que crean un mundo común con grados diversos de éxito en el intercambio y la negociación, éxito que dependerá de las garantías para el cumplimiento de las reglas. Las reglas formales establecen mecanismos para garantizar el cumplimiento mediante terceros, es

2 En "El misterio del crecimiento económico", Helpman (2004) presenta una reseña de estudios que destacan la importancia de las instituciones y la política para el desarrollo. Hace poco Acemoglu \& Robinson (2013) han ampliado sus aportaciones a la comprensión de la incidencia de las instituciones en las condiciones del desarrollo de las naciones.

3 Esta cuestión la detallaremos más adelante desde una perspectiva sociológica. 
el caso de las instituciones del Estado con poder coercitivo. Las informales se autorrefuerzan, esto es, la garantía de su cumplimiento es por reputación o sanción de la propia colectividad.

Por tanto, la formalidad es legalidad susceptible de aplicación universal, esto comporta que las reglas son de aplicación general e impersonal, formalmente igual para todos. En la institucionalidad informal el orden de la regla es garantizado por tradición, en el sentido de que es práctica regular, tácita, y recíprocamente aceptada y autosancionada, susceptible al particularismo. Sobre el particularismo o clientelismo en sentido amplio, Guillermo O'Donnell sostiene que coexiste en el complejo institucional de la poliarquía: "El particularismo — y su contraparte, concepciones y prácticas neopatrimonialistas y delegativas de gobierno- es antagónico con uno de los principales aspectos del complejo institucional de la poliarquía: la distinción, en términos legales, normativos y de comportamiento, entre la esfera pública y la privada." (O’Donnell, 1996: p. 233).

El aporte de O'Donnell ${ }^{4}$ insertó la institucionalización informal como componente central de la democratización en Latinoamérica. El politólogo argentino señala que el particularismo en estas naciones también se ha institucionalizado, yuxtapuesto a la institucionalización de las elecciones, por lo que se debe distinguir entre las poliarquías antiguas y las nuevas, ya que en éstas las instituciones informales como el clientelismo y el particularismo son dominantes, principalmente a través de prácticas delegativas.

Lo informal se instituye no sólo en su figura de violación de la ley, ${ }^{5}$ también se pueden identificar instituciones informales que se caracterizan por actuar en los huecos y vacíos legales o normativos, es el ejemplo del intercambio de cargos por lealtad política. Inclusive existen prácticas políticas informalmente instituidas que después se formalizan. Pero esto no es garantía de cumplimiento, el particularismo implica que en aras de intereses parciales, las conductas de los actores sociales se apartan del cumplimiento de la ley positiva.

Las reglas no escritas son identificables en las prácticas y opiniones, en las trayectorias, en la acción incierta de los actores; lo informal es escurridizo, tiene una predilección por la opacidad. Es ámbito de cooperación, pero también de inequidades. Como apunta Melucci (1999: p. 197), la acción social antes que en las organizaciones, comienza en grupos, redes y cadenas informales de individuos. En la informalidad se tejen redes de interés, se configuran alianzas políticas y se presenta el reclutamiento partidista de familias, grupos empresariales,

4 Consúltese también la reflexión original de O’Donnell (1994) sobre la democracia delegativa en América Latina.

5 Confróntese con Leiras (2004), para quien lo común de las instituciones políticas informales es la violación de leyes positivas o de normas reconocidas.

C. A. Navarrete Ulloa | Institucionalismo informal: tras las huellas de un discurso institucionalista informal Perfiles Latinoamericanos, 24(47) | FLACso México | pp. 283-306 | DoI: 10.18504/pl2447-003-2016 
comerciantes formales o informales, grupos sindicales, agrupaciones profesionales, burocracias o grupos delincuenciales. ${ }^{6}$

El ámbito de lo informal no es espacio exclusivo de bajos instintos, pero para fines de estudio del poder sí es conveniente entender que es su espacio natural. En la informalidad se siembra y crece el rumor, la mentira y el engaño, aunque también la negociación y la concertación; pueden surgir redes de complicidad y criminalidad, como redes de cooperación y desarrollo (capital social).

Abajo se continúa con la revisión de la dispersa literatura sobre la informalidad. A partir de la literatura identificada se buscará los componentes principales de las instituciones informales, pensando sobre todo en el estudio de las instituciones políticas, además, queda implícito el interés por el desarrollo de un constructo analítico para las instituciones informales identificadas al interior de los partidos políticos.

\title{
Instituciones informales: la literatura
}

\begin{abstract}
Pero, en realidad, las instituciones están hechas de significaciones socialmente sancionadas y de procedimientos creadores de sentidos. Estas significaciones son esencialmente imaginarias $-\mathrm{y}$ no racionales, funcionales o reflejos de la realidad—, son significaciones imaginarias sociales.
\end{abstract}

Cornelius Castoriadis

Arriba se ha observado que el análisis de las instituciones informales se inspira en los desarrollos teóricos del nuevo institucionalismo. Si bien es reconocida la importancia de la cuestión, la literatura que atiende el tema es más bien escasa y desarticulada. El objetivo de esta sección es atender la parte informal de las instituciones. Más que centrarnos en la literatura institucionalista, se indagará en diversas ramas del saber, con la intención de estructurar una propuesta conceptual a fin de hallar elementos articuladores para el estudio de las instituciones informales.

La investigación teórica responde al interés de reducir ambigüedades conceptuales y establecer bases para vincular sin vaguedad el significado de la categoría institución informal con referentes concretos. Se rescata la esencia de las reglas para el análisis de los conceptos de Giovanni Sartori, quien sugiere que en la

6 Prats (2008) presenta varios ejemplos. En este artículo se amplían las referencias en la sección sobre la literatura de las instituciones informales. 
reconstrucción de un concepto se debe recopilar un conjunto significativo de abordajes (definiciones) para extraer las características del conjunto y organizar en matrices las características significativas. El sondeo implica tres momentos: “a) la determinación de la etimología; b) la reconstrucción de la Geistesgeschichte (historia intelectual) de una palabra; c) el análisis textual de las fuentes o de los autores más relevantes." (Sartori, 2012: p. 230).

Para comprender que el estudio de las instituciones informales es un campo marginalmente abordado, se revisarán en principio las obras clásicas y recientes de la sociología, la antropología y el psicoanálisis. Enseguida se revisará la literatura que aborda el tema en revistas de ciencias sociales y tesis doctorales que se han presentado en diversas latitudes del mundo en años recientes.

\section{Clásicos de las ciencias sociales}

La cultura es la categoría fundamental de estudio para la antropología, y en ella siempre subyace la noción de institución, la cual excepcionalmente es elevada a categoría central. ${ }^{7}$ De hecho, en las definiciones de cultura la idea de institución se encuentra centralmente en las ideas de tradiciones, pautas de conducta y hábitos. Una definición influyente de cultura la confirma como "el conjunto aprendido de tradiciones y estilos de vida, socialmente adquiridos, de los miembros de una sociedad, incluyendo sus modos pautados y repetitivos de pensar, sentir y actuar (es decir, su conducta)" (Harris, 1998: pp. 19-20).

Para Murdock (1997: pp. 66, 69), las instituciones son el conjunto de costumbres establecidas en la sociedad humana, que rodean a los impulsos y su satisfacción. Herskovits ([1948] 1984), por su parte, entiende que las instituciones imponen las conformidades de los individuos en interés de la adaptación y supervivencia; "representan respuestas formalizadas consagradas y 'sancionadas' a las exigencias de la vida" (Herskovits ([1948] 1984: pp. 255, 262). Antropológicamente hablando la cultura implica a) tradiciones, $b$ ) costumbres, $c$ ) pautas de conducta. ${ }^{8}$ En esencia, de la formación de hábitos se deriva toda conducta cultural.

En la construcción de su corpus conceptual del mundo de la vida cotidiana, Alfred Schutz (1973) considera que para explicar la acción y el pensamiento humanos se debe comenzar con la descripción de la realidad que parece evidente al hombre que permanece en actitud natural. Esto corresponde al mundo de la

Véase, por ejemplo, Malinowski ([1948]1976: pp. 52-55, 60).

8 Herskovits afirma que las pautas de conducta comprenden acciones y el significado conferido al acto; en su forma institucionalizada "moldean la conducta y plasman las actitudes, creencias y puntos de vista” (Herskovits, [1948] 1984: p. 224). 
vida cotidiana, ámbito de la acción (intervención y capacidad de transformación) del ser humano y de su interacción con otros individuos, por lo que es también el mundo común y comunicativo. Aquí ocurren explicitaciones que antes ya se dieron, de manera que se construye una realidad familiar ( $y$ asi sucesivamente). De ello se desprende la posibilidad de recurrir a actos ya ensayados exitosamente, creándose una estructura del mundo constante y la capacidad de operar en el mundo con certidumbres.

Las reflexiones de Schutz \& Luckmann, que se enfocan al nivel micro de la vida social, constituyen un aporte al estudio de las instituciones. El mundo de la vida cotidiana es el mundo de las instituciones en su aspecto informal, aquél que en lo cotidiano experimentan los individuos y dan como presupuesto (está dado de modo incuestionable), "es la experiencia sedimentada que ha pasado la prueba y cuya validez no necesita ser examinada por los individuos" (Schutz \& Luckmann, [1973] 2001: p. 29); es el acervo de conocimiento que si bien está rodeado de incertidumbre, a la vez proporciona una guía para la solución de los problemas.

En La construcción social de la realidad, Berger \& Luckmann ([1968] 2001) plantean que la legitimación implica modos de "explicar" y justificar las instituciones. Las instituciones surgen con la "tipificación recíproca de acciones habitualizadas" y controlan la acción humana con el establecimiento de pautas, de manera que el individuo las experimenta como un hecho externo y coercitivo ya que las instituciones invocan autoridad. El engranaje legitimador genera oportunidades y restricciones, iniciados y profanos, y el mecanismo de conservación de estas relaciones, al punto que las identidades se reifican. El individuo así pierde noción, olvida que es partícipe de la creación del mundo humano porque la legitimación le indica por qué las cosas son lo que son. En otras palabras, las instituciones son los límites de la interacción humana, establecen linderos, los canales por los cuales la acción de los individuos se considera aceptable, con lo que se finca el escenario de oportunidades para la acción estratégica. Esto implica un ámbito de certidumbre y otro de incertidumbre: el primero otorgado por las pautas, el segundo por la forma en que se abordan dichas pautas. Quien reduce el ámbito de incertidumbre incrementa sus opciones de acción.

Después de todo, la estructura social es un horizonte abierto de posibilidades para sus miembros (Berger \& Pullberg, 1965: p. 202). En el proceso de socialización se estrechan los horizontes y emerge un mundo que es considerado como dado, vivido y como destino necesario (Berger \& Pullberg, 1965: p. 203). Las instituciones se experimentan como si tuvieran realidad propia, aparecen "como dadas, inalterables y evidentes por sí mismas" (Berger \& Luckmann, [1968] 2001: pp. 80, 82). 
En la sociología encontramos bases para integrar a la reflexión de las instituciones informales las nociones microsociales de la vida cotidiana, pero también las macrosociales, las estructuras sociales y la lógica de la legitimación de la vida institucional. Abundaremos sobre estas categorías en el apartado de análisis empírico.

Freud comprende la cultura por contraposición a natura, en el sentido de que está constituida por la suma de producciones e instituciones que nos distancian de los antecesores animales, lo que protege al hombre contra la naturaleza, y regula las relaciones entre sí (Freud, 2003: p. 3033). Es rasgo característico de la cultura la forma en que son reguladas las relaciones de los hombres, lo que quiere decir que la cultura impone restricciones a las posibilidades de satisfacción de instintos primitivos.

El principio de la regulación de relaciones sociales surge con la sustitución del poderío individual por el de la comunidad, significado con la alianza fraterna entre hijos para triunfar sobre el padre en el entendido de que la asociación puede ser más poderosa que el individuo aislado (Freud, 2003: p. 3039). A este momento del proceso de la cultura Freud lo llama fase totémica de la cultura, en la cual ya se encuentra la constitución de la alianza en función de restricciones que se imponen los hermanos.

Así, el proceso cultural se caracteriza por los cambios que impone a las disposiciones instintuales del hombre. Algunos instintos son regulados por el carácter, otros son desplazados. Un resultado ineludible de esta evolución es la frustración cultural, causa de la hostilidad de los individuos contra la cultura.

La cultura posibilita la vida en común, y sus rasgos la facilitan. No obstante, el sistema que la genera lleva inmanente el principio fundamental que la crea y cuestiona (eros y tánatos), dualidad de amor y muerte, creación y destrucción, orden y agresión. El amor es en su origen plenamente sexual, con la cultura surge el amor coartado en su fin, el fin inhibido. Las familias surgen del amor genital, las "amistades" del fin inhibido. De ello surge una tensión natural entre familia y la comunidad social más amplia: "El modo de vida en común filogenéticamente más antiguo, el único que existe en la infancia, se resiste a ser sustituido por el cultural, de origen más reciente." (Freud, 2003: p. 3041). En suma, la evolución individual tiende al egoísmo o la felicidad, en tanto que el proceso cultural instituye restricciones, mismas que establecen límites a las pretensiones egoístas individuales.

Las disposiciones culturales que restringen la satisfacción de instintos primitivos, entre ellos la agresión, ${ }^{9}$ son de tres tipos: 1) la comunidad basada en

9 Considerada por Freud como disposición instintiva innata y autónoma del ser humano, y el mayor obstáculo que enfrenta la cultura (2003: p. 3052).

C. A. Navarrete Ulloa | Institucionalismo informal: tras las huellas de un discurso institucionalista informal Perfiles Latinoamericanos, 24(47) | FLACso México | pp. 283-306 | DoI: 10.18504/pl2447-003-2016 
vínculos de fin inhibido; 2) restricciones de la vida sexual, y 3) el precepto ideal de amar al prójimo como a sí mismo (la norma). Estas disposiciones se sintetizan en una, la interiorización de la agresión, que es interiorización de la autoridad e interiorización de la norma: la agresión es dirigida contra el propio $y o$, incorporándose como súper-yo, el cual asume la función de "conciencia", la tensión que surge es llamada por Freud sentimiento de culpabilidad. El resultado es el control cultural de la agresión por la vía de limitaciones autoimpuestas por miedo a la autoridad o por temor al súper-yo. En otras palabras, la cultura restringe la satisfacción de instintos primitivos (miedo a la autoridad) y limita la tendencia a la agresión mediante la amenaza de castigo (el súper-yo).

No obstante, la capacidad generadora de orden de la cultura está limitada por la transgresión, faltas en la interiorización de la norma y las propias circunstancias, "mientras la suerte sonríe al hombre, su conciencia moral es indulgente y concede grandes libertades al yo; en cambio, cuando la desgracia le golpea, hace examen de conciencia" (Freud, 2003: 3055).

En suma, el enfoque freudiano de la cultura nos permite comprender las bases psicológicas que llevan a los individuos a integrar de manera diversas las normas, e incluso a comportarse no sólo en función de los mecanismos de interiorización de la norma sino además en respuesta a circunstancias de cálculo racional y/o emocional.

Para finalizar, vale resaltar que en los sistemas complejos las relaciones políticas adquieren su máxima importancia, singularmente los sistemas de representación política, y los mecanismos de complementación que posibilitan su continua adaptación que la misma complejidad exige. La reducción de la incertidumbre en un mundo que experimenta cambios inusitadamente rápidos exige instrumentos regulatorios de la complejidad. Y es precisamente en la complejidad del mundo moderno que aparece la necesidad de una mayor especialización y estratificación social con lo que surge la burocracia, y los partidos políticos (cfr. Melucci, 1999: pp. 167-168).

\section{Estudios contemporáneos}

En los próximos apartados se presenta el resultado de un sondeo en revistas científicas y tesis doctorales. Por cuestiones de espacio sólo se refieren las obras identificadas como más significativas, pero conviene expresar que la investigación de tesis doctorales se elaboró a parir de la base de datos ProQuest Dissertation and Thesis. El método de búsqueda fue por palabras clave y bola de nieve (Devine, 1997). Con las obras seleccionadas se realizó una triangulación de investigadores y enfoques teóricos (Suárez Relinque, Del Moral Arroyo \& González Fernández, 
2013). El resultado del análisis se organiza en cinco secciones: $a$ ) defensa de la informalidad, $b$ ) orientaciones cognitivas, $c$ ) orientación cultural, $d$ ) economía informal y e) orientación política. Algunas cuestiones se entrelazan en los enfoques propuestos. Se buscó en principio una agrupación de la literatura por comunidades disciplinarias, y en segunda instancia por el tratamiento axiológico.

\section{a. Defensa de la informalidad.}

Aun cuando es predominante la literatura que analiza el orden y el progreso de la sociedad en el marco de las instituciones formales, existe un grupo de estudiosos con especial interés en desenfocar dichas reflexiones, y poner el horizonte en los fenómenos sociales que sostienen la informalidad. La relación formalinformal sugiere dos resultados: uno funcional o de solución de problemas, y uno disfuncional caracterizado por el clientelismo, corrupción y patrimonialismo como fenómenos que socavan las instituciones del Estado (Helmke \& Levitsky, 2004). Pero alternativamente y en ocasiones, las instituciones informales refuerzan o sustituyen a las formales. No sólo éstas son incompletas, sino que en ocasiones aquéllas son la mejor segunda estrategia frente a la inoperancia de las primeras (cfr. O’Donnell, 1996).

El estudio de la vida interna de los partidos políticos ha llevado a la identificación de una rica institucionalidad informal, en especial al análisis de las organizaciones partidistas informales en Latinoamérica. La debilidad de la estructura formal de estos partidos políticos puede explicarse atendiendo a los procesos políticos. Un caso concreto son las organizaciones de base no reconocidas en estatutos o registradas oficialmente, no obstante que sean la substancia de los partidos en el reclutamiento de activistas, selección de candidatos y recaudación de fondos (Freidenberg \& Levitsky, 2006, 2007).

Algunos autores proponen que el capital político de un partido puede radicar en las prácticas informales, es el caso del Partido de la Revolución Mexicana (PRD), que aglutina amplios sectores no atendidos por el Estado en una relación pobres-jefes o patrones políticos y/o económicos, en búsqueda de beneficios recíprocos (Hilgers, 2007; Martínez, 2005). La cuestión implica que en la lucha política unos partidos establecen sistemáticamente maquinarias políticas, soportadas en una amplia distribución de recursos; otros, fincan su capital político en relaciones patrón-cliente. Esta perspectiva deduce que las estructuras informales son un fenómeno no exclusivo de sociedades tradicionales "las relaciones personales funcionan como el pegamento que mantiene unido al sistema" (Hilgers, 2007: p. 40). Una tesis que se refuerza por los trabajos de Liebert (2007) y Stacey (2007).

Las redes sociales y las comunidades basadas en la confianza son posibles de identificar como instituciones informales en la sociología y en los estudios 
sobre la gobernanza, el capital social y la gestión. Estas expresiones positivas de lo informal pueden abordarse desde un marco conceptual construido con los patrones sociales comunes en las organizaciones: las comunidades y las redes (High, 2005).

\section{b. Orientaciones cognitivas.}

Como rama emergente de la teoría económica, la economía cognitiva busca explicar y modelar el comportamiento de los agentes mediante hipótesis psicológicamente significativas (Patalano, 2007). El enfoque busca el cruce de disciplinas pero también se nutre de la historia del pensamiento económico, de allí que recurra a la reinterpretación de autores como Veblen y Hayek. Se entiende que la coordinación recíproca de comportamientos es resultado de hábitos mentales (Veblen), establecidos como instituciones. Conforme a Hayek serían normas o reglas de comportamiento que coordinan las expectaciones de los agentes, facilitando sus interacciones por la vía de hacer predecibles las acciones de otros agentes. Cognitivamente se plantea que las instituciones establecen restricciones que son internalizadas por los individuos, así consolidan los rasgos específicos de la realidad externa, haciéndola más estable y comprensible (Patalano, 2007: p. 224).

Este enfoque se orienta con el pensamiento de Mantzavinos y Castoriadis, busca establecer puentes en la interacción entre mente e instituciones, y propone marcar el acento en los roles de la imaginación y la afectividad, apoyándose en las nociones lacanianas de imaginario, simbólico y real. Así, se entienden las instituciones como sistemas de relaciones simbólicas que son socialmente reconocidas y sancionadas. Los patrones institucionales simplifican el proceso de pronosticar proveyendo el recurso de expectativas confiables. Las instituciones, en tanto sistemas de relaciones simbólicas, se entienden como una dialéctica medio ambiente-sujeto, sujeto-medio ambiente. Por el lado de lo real, las instituciones; en lo imaginario, las representaciones mentales que se manifiestan simbólicamente. Son fenómenos que se entrelazan y establecen mecanismos resistentes al cambio, pero plásticos.

\section{c. Orientación cultural.}

El estudio comparativo encuentra soportes en el análisis de las variables de la cultura política abordadas como instituciones informales. De esta manera se buscan explicaciones al nivel de desarrollo de las naciones, o del tipo de instituciones (formales o informales) sobre las que se funda el desarrollo económico.

El estudio de la función de las instituciones en el desempeño económico de las naciones, ha sido una fuente nutrida de investigación desde la propuesta teórica de Douglas North (1993). Estudios recientes identifican que la infor- 
malidad como cultura política es un factor central del desarrollo. Asimismo, investigaciones empíricas refutan la hipótesis de que las instituciones informales sean la explicación del subdesarrollo, o que sean privativas de países en vías de desarrollo.

En Estados Unidos de Norteamérica, los obreros inmigrantes propician a) que las instituciones informales compensen a las formales ineficientes (interacción sustitutiva); b) que las redes sociales de inmigrantes socaven y compitan con las reglas de inmigración (interacción rival), y c) que mejore la eficacia y eficiencia de las formales al buscar las informales las mismas metas (interacción complementaria) (Liebert, 2007). La investigación del fenómeno migratorio de Kirguistán a Estados Unidos revela cómo se rutinizan conductas contrarias al orden legal, por lo que surge un orden informal paralelo. Hechos como la intermediación migratoria, agencias de empleo para inmigrantes, redes informales proveedoras de identidades y albergues especiales para inmigrantes ilegales, que Liebert presenta como instituciones informales, son manifestaciones del establecimiento de normas de conducta de forma regular y compartidas por esa comunidad. Incluso "hechos institucionales" como las filas o colas, o los ejemplos arriba referidos, tienen efecto de realidad, son hechos que instituyen restricciones (MacCormick, 1998); o, en términos de North, estructuran incentivos en el intercambio humano (North, 1993: p. 13).

\section{d. Economia informal.}

La informalidad como actividad económica ha sido ampliamente estudiada, incluidos el clientelismo y la corrupción. Desde luego que las diversas orientaciones se entrelazan, y algunas se superponen en algunas de sus áreas, en lo cultural y lo económico.

La actividad económica informal presenta diversas expresiones: a) irregular, entendida como cuasi-legal —ilegal por evadir impuestos y otras leyes_-, más que criminal; $b$ ) oculta, es la manifestación criminal de la informalidad (robo, malversación, venta de bienes robados, etcétera); c) no oficial, que opera dentro de lo oficial legítimo, pero utilizando favores y privilegios como medio de intercambio, y $d$ ) social, que opera fuera de lo formal y utiliza el trueque como medio de intercambio (Henry \& Sills, 2006).

En el estudio de la economía informal se ha explicado el comercio informal como procesos de adaptación a lo social más que a necesidades económicas, de manera que de la relación formal-informal, con sus aspectos mutuamente alentadores y destructores, se desprende el desempeño económico. En suma, se problematiza la relación formal-informal, como los extremos del mismo continuo, o como mezcla de diversos grados entre ambos elementos. Lo que lleva a inferir que están en una relación dialéctica dinámica. Las economías formales 
e informales se relacionan constitutivamente en relaciones convergentes y divergentes de soporte y disolución (Henry \& Sills, 2006: p. 280).

El mismo proceso de reforma estructural, que naturalmente se orienta al fortalecimiento de instituciones formales, conlleva a una narrativa paralela menos explícita, como lo demuestra el análisis del papel de las instituciones informales (clientelismo y corrupción), en la reforma de telecomunicaciones en Kenia (Macharia, 2007).

\section{e. Orientación politica.}

Mientras en la economía se puede distinguir a primera vista un objeto de atención inmediato —esto es, la economía informal—, en la ciencia política esto es menos claro: no se habla de política informal. En este campo los estudiosos entienden por instituciones informales a fenómenos tan dispares como bromear (Peltier, 2007), ${ }^{10}$ la corrupción, clientelismo y patrimonialismo (Erdmann \& Engel, 2006), el caciquismo (Knight \& Pansters, 2005; Middlebrook, 2009), los acuerdos políticos y pactos de caballeros entre caciques (Barrero, 2014), o más generalmente, el capital social y la cultura política (Helmke \& Levitsky, 2004; Stacey, 2007).

La corrupción es un fenómeno social que se presenta en quebranto de lo estatuido, y en tal sentido es informal. La literatura sobre la corrupción es tan vasta como complejo es el tema (Morgan, 1998). ${ }^{11}$ El término se ha usado para designar un amplio abanico de actividades ilícitas e ilegales. Las definiciones más destacadas enfatizan el abuso del poder público para beneficio personal. Ello genera fronteras difusas entre las esferas pública y privada en función de las características de las instituciones políticas y la calidad de la participación ciudadana (Johnston, 2005). Pero la corrupción implica la acción de actores egoístas y racionales, que atienden a dilemas políticos con la consecuencia de que no siempre la conducta correcta conduce al mejor resultado (Geddes, 1994).

En el estudio de los regímenes híbridos, llama la atención la noción de neopatrimonialismo (Erdmann \& Engel, 2006), que corresponde a una mezcla de dos tipos de dominación política: la patrimonial y la racional burocrática, rasgos comunes a otra forma de poder informal: la del cacique. El caciquismo es común en áreas rurales, pero en sus formas modernas se le encuentra en partidos políticos, sindicatos, asentamientos urbanos irregulares e incluso en universidades. El cacique es un jefe local o regional cuya dominación personalista descansa

10 Peltier plantea la idea poco convencional de que la institucionalización de las bromas (literalmente hablando) es un instrumento de legitimación del Estado.

11 Para profundizar, véanse Geddes (1994), Johnston (2005), Park, Thelwall \& Kluver (2005), Reed (1996), y Van Biezen \& Kopecky (2007). 
en relaciones de parentesco, alianzas patrón-cliente y el control sobre recursos de patronazgo, incluida la amenaza o el uso de la fuerza física en contra de sus rivales. $\mathrm{Y}$ en sus formas modernas, tal cacique puede ocupar cargos formales de elección popular y posiciones administrativas en organismos públicos $(\mathrm{Na}-$ varrete \& Dolores, 2014), razón por la que se le debe entender como fenómeno coexistente con la democracia, en tensas relaciones dialécticas en equilibrio dinámico (Middlebrook, 2009).

Las negociaciones entre los actores organizacionales centrales de la Unión Europea - el Consejo, la Comisión y el Parlamento europeos- pueden ser entendidas como reglas informales (Stacey, 2007). Y éstas llevan a concluir que, al canalizar el comportamiento de los actores en ausencia de sanción externa, se instauran como instituciones informales. Tal vez sean no intencionadas (convenciones informales) o creadas conjuntamente (acuerdos y preceptos informales). Los acuerdos son contratos no oficiales; las convenciones, prácticas que se rutinizan en el transcurso del tiempo; son reglas de costumbre, base del desarrollo de expectativas que las infusionan de un mínimo de obligatoriedad (Stacey, 2007: p. 29).

En general se observa que el enfoque de la ciencia política utiliza de forma diversa la categoría de estudio. Quizás lo común entre estas aproximaciones es que atribuyen la categoría informal a lo que ocurre fuera del espacio de lo oficial, en unos casos más cercanos a lo formal que otros. Las cinco orientaciones encontradas en la literatura dibujan un complejo de abordajes que ofrece guías generales para la mejor comprensión de las instituciones informales. Además, la literatura clásica de las ciencias sociales tiene en el tema de los hábitos y los patrones de conducta conceptos que construyen puentes entre disciplinas para comprender la institucionalidad informal.

\section{Análisis empírico}

Los abordajes teóricos y empíricos analizados se sintetizan en una matriz conceptual (tabla 1). Ésta se integra de las categorías significativas encontradas, las representaciones positivas y negativas de las instituciones informales, las formas como se expresan (manifestaciones) y/o las fuentes de las que surgen, y finalmente cita los ejemplos. Conviene advertir que la matriz es el resultado de distintas fases analíticas realizadas con los mapas conceptuales y la codificación de contenidos textuales, aunque por el alcance del artículo no se puede ahondar en la descripción del análisis subyacente.

Las categorías centrales de la literatura analizada permiten concluir que las instituciones surgen del proceso de la cultura porque éste hace posible la 
comunidad de los individuos y la acción social por medio de la inhibición de los instintos primitivos, entre ellos principalmente el de la agresión. La mejor forma de comprender las instituciones informales es visualizarlas como sistemas de relaciones simbólicas, con lo que se engloba al mundo de la vida cotidiana que se vive como destino manifiesto. Esto lo ha sintetizado Castoriadis (2013) como significaciones imaginarias socialmente sancionadas, entre las que se encontraría el particularismo como sistema de dominación que se legitima sobre todo por tradición, experiencia sedimentada que condiciona el escenario de posibilidades.

No se puede hablar de instituciones informales sin el prerrequisito de las prácticas que se rutinizan. Así, se posibilita el surgimiento de hábitos y costumbres, se establecen pautas de conducta y se constituyen las reglas de comportamiento, lo que en su conjunto significa tradiciones y estilos de vida.

Tabla 1. Matriz de componentes principales identificados en la literatura del institucionalismo informal

\begin{tabular}{|c|c|c|c|c|c|c|}
\hline Autor & $\begin{array}{l}\text { Categorías } \\
\text { explicativas }\end{array}$ & $\begin{array}{l}\text { Expresión } \\
\text { funcional }\end{array}$ & $\begin{array}{l}\text { Expresión } \\
\text { disfuncional }\end{array}$ & $\begin{array}{l}\text { Manifesta- } \\
\text { ciones }\end{array}$ & Fuente & Ejemplos \\
\hline $\begin{array}{l}\text { Primeras } \\
\text { inferencias }\end{array}$ & & $\begin{array}{l}\text { Trayectorias } \\
\text { / Redes de } \\
\text { cooperación }\end{array}$ & $\begin{array}{l}\text { Redes de } \\
\text { complici- } \\
\text { dad }\end{array}$ & $\begin{array}{l}\text { Lo no formal / } \\
\text { Vacíos legales }\end{array}$ & $\begin{array}{l}\text { Pluralidad } \\
\text { de poderes } \\
\text { incidiendo en } \\
\text { el juego }\end{array}$ & $\begin{array}{l}\text { Capital social } \\
\text { / Clientelismo / } \\
\text { Personalismo / } \\
\text { Caciquismo }\end{array}$ \\
\hline Melucci & Acción social & & & $\begin{array}{l}\text { Pautas de } \\
\text { interacción }\end{array}$ & & \\
\hline O'Donell & Particularismo & & Clientelismo & & & \\
\hline Mariscal & & $\begin{array}{l}\text { Orientan el } \\
\text { comporta- } \\
\text { miento }\end{array}$ & $\begin{array}{l}\text { El juego no } \\
\text { es neutro }\end{array}$ & $\begin{array}{l}\text { Cómo se } \\
\text { accede al pro- } \\
\text { ceso político }\end{array}$ & & \\
\hline $\begin{array}{l}\text { Ayala } \\
\text { Espino }\end{array}$ & & & & & $\begin{array}{l}\text { Contratos } \\
\text { imperfectos }\end{array}$ & \\
\hline $\begin{array}{l}\text { Freidenberg } \\
\text { y Levitsky }\end{array}$ & & & & & & $\begin{array}{l}\text { Organizaciones } \\
\text { de base / redes } \\
\text { comunitarias }\end{array}$ \\
\hline Chris High & & Capital social & & & $\begin{array}{l}\text { Valores com- } \\
\text { partidos }\end{array}$ & $\begin{array}{l}\text { Redes sociales } \\
\text { y comunidades }\end{array}$ \\
\hline $\begin{array}{l}\text { Thorstein } \\
\text { Veblen }\end{array}$ & Honor / Hábitos & & & & $\begin{array}{l}\text { Hábitos } \\
\text { mentales }\end{array}$ & \\
\hline $\begin{array}{l}\text { Friedrich } \\
\text { Hayek }\end{array}$ & $\begin{array}{l}\text { Reglas de } \\
\text { comportamiento }\end{array}$ & & & & & \\
\hline Liebert & & $\begin{array}{l}\text { Interacción } \\
\text { sustitutiva o } \\
\text { complemen- } \\
\text { taria }\end{array}$ & $\begin{array}{l}\text { Interacción } \\
\text { rival }\end{array}$ & & & $\begin{array}{l}\text { Agencias y de } \\
\text { empleo para } \\
\text { inmigrantes / } \\
\text { Albergues para } \\
\text { inmigrantes } \\
\text { ilegales }\end{array}$ \\
\hline Patalano & $\begin{array}{l}\text { Sistemas de } \\
\text { relaciones } \\
\text { simbólicas }\end{array}$ & $\begin{array}{l}\text { Resistentes al } \\
\text { cambio, pero } \\
\text { plásticas }\end{array}$ & & & & \\
\hline Henry y Sills & $\begin{array}{l}\text { Relaciones de } \\
\text { soporte y disolu- } \\
\text { ción entre formas } \\
\text { institucionales }\end{array}$ & $\begin{array}{l}\text { No oficial / } \\
\text { Social }\end{array}$ & $\begin{array}{l}\text { Cuasi-legal } \\
\text { / Oculta }\end{array}$ & & & $\begin{array}{l}\text { Evasión de } \\
\text { impuestos, } \\
\text { malversación, } \\
\text { intercambio de } \\
\text { favores, trueque. }\end{array}$ \\
\hline
\end{tabular}


Tabla 1. Matriz de componentes principales identificados en la literatura del institucionalismo informal (continuación)

\begin{tabular}{|c|c|c|c|c|c|c|}
\hline Autor & $\begin{array}{l}\text { Categorias } \\
\text { explicativas }\end{array}$ & $\begin{array}{l}\text { Expresión } \\
\text { funcional }\end{array}$ & $\begin{array}{l}\text { Expresión } \\
\text { disfuncional }\end{array}$ & $\begin{array}{l}\text { Manifesta- } \\
\text { ciones }\end{array}$ & Fuente & Ejemplos \\
\hline $\begin{array}{l}\text { Amanda } \\
\text { Morgan }\end{array}$ & & & $\begin{array}{l}\text { Corrupción, } \\
\text { lo oculto. }\end{array}$ & & & \\
\hline $\begin{array}{l}\text { Barbara } \\
\text { Geddes }\end{array}$ & & $\begin{array}{l}\text { Dilemas } \\
\text { políticos }\end{array}$ & & & & \\
\hline Middlebrook & & $\begin{array}{l}\text { Coexistente } \\
\text { en demo- } \\
\text { cracia }\end{array}$ & Caciquismo & & & \\
\hline Stacey & $\begin{array}{l}\text { Prácticas que se } \\
\text { rutinizan }\end{array}$ & & & $\begin{array}{l}\text { Reglas de } \\
\text { costumbre / } \\
\text { Contratos no } \\
\text { oficiales }\end{array}$ & $\begin{array}{l}\text { Conven- } \\
\text { ciones / } \\
\text { Acuerdos y } \\
\text { preceptos }\end{array}$ & \\
\hline Murdock & Costumbres & Adaptación & & Conformidades & & \\
\hline Herskovits & $\begin{array}{l}\text { Pautas de } \\
\text { conducta }\end{array}$ & & & & & \\
\hline Harris & $\begin{array}{l}\text { Tradiciones y } \\
\text { estilos de vida }\end{array}$ & & & & & \\
\hline $\begin{array}{l}\text { Alfred } \\
\text { Schutz }\end{array}$ & $\begin{array}{l}\text { Mundo de vida } \\
\text { cotidiana / Expe- } \\
\text { riencia sedimen- } \\
\text { tada / acervo de } \\
\text { conocimiento }\end{array}$ & $\begin{array}{l}\text { Mundo } \\
\text { común y co- } \\
\text { municativo }\end{array}$ & & $\begin{array}{l}\text { Escenario de } \\
\text { posibilidades }\end{array}$ & $\begin{array}{l}\text { Realidad } \\
\text { típicamente } \\
\text { familiar }\end{array}$ & \\
\hline $\begin{array}{l}\text { Berger y } \\
\text { Luckmann }\end{array}$ & Legitimidad & $\begin{array}{l}\text { Invocan } \\
\text { autoridad }\end{array}$ & & $\begin{array}{l}\text { Se experimen- } \\
\text { tan como si tu- } \\
\text { vieran realidad } \\
\text { propia }\end{array}$ & $\begin{array}{l}\text { Tipificaciones } \\
\text { recíprocas de } \\
\text { acciones ha- } \\
\text { bitualizadas }\end{array}$ & $\begin{array}{l}\text { Formas de } \\
\text { sanción social }\end{array}$ \\
\hline $\begin{array}{l}\text { Berger y } \\
\text { Pullberg }\end{array}$ & $\begin{array}{l}\text { Mundo vivido } \\
\text { como destino } \\
\text { necesario }\end{array}$ & & & $\begin{array}{l}\text { Horizonte } \\
\text { abierto de } \\
\text { posibilidades }\end{array}$ & $\begin{array}{l}\text { Estructura } \\
\text { social }\end{array}$ & \\
\hline $\begin{array}{l}\text { Doyle P. } \\
\text { Johnston }\end{array}$ & & $\begin{array}{l}\text { Estructuras } \\
\text { de credibi- } \\
\text { lidad }\end{array}$ & & & $\begin{array}{l}\text { Cosmovisión } \\
\text { subyacente } \\
\text { que las sopor- } \\
\text { ta y legitima }\end{array}$ & \\
\hline $\begin{array}{l}\text { Sigmund } \\
\text { Freud }\end{array}$ & $\begin{array}{l}\text { El Fin inhibido } \\
\text { / El proceso de } \\
\text { la cultura / } \\
\text { Súper-yo }\end{array}$ & $\begin{array}{l}\text { Renuncia a } \\
\text { satisfacciones } \\
\text { instintuales }\end{array}$ & $\begin{array}{l}\text { Disposi- } \\
\text { ciones } \\
\text { instintivas } \\
\text { de agresión }\end{array}$ & $\begin{array}{l}\text { Formas de } \\
\text { internalización } \\
\text { de la autoridad }\end{array}$ & $\begin{array}{l}\text { Disposiciones } \\
\text { instintuales } \\
\text { del hombre }\end{array}$ & \\
\hline
\end{tabular}

Fuente: Elaboración propia.

Las instituciones informales tienen dos expresiones: una funcional y otra disfuncional. Se logran equilibrios culturales a través de redes de cooperación, estructuras de credibilidad y, esencialmente, por la renuncia a instintos posibilitando la adaptación. Así, lo social no-oficial abre posibilidades de intervención de las instituciones informales como sustitución de las formales cuando éstas son ineficientes, o de complementación cuando se refuerzan. Esta situación es de amplia relevancia en las sociedades complejas de la modernidad, donde la confianza interpersonal es el cemento de la cooperación.

Los individuos interactúan en un mundo común por el que se establecen estructuras de credibilidad que disminuyen la incertidumbre y eficientan el intercambio social y económico. En este sentido, las instituciones informales son 
sistemas de relaciones simbólicas que instituyen estructuras de credibilidad en un mundo común y comunicativo. En este escenario intervienen los políticos y gobernantes, quienes no están exentos de interpretar la estructura de oportunidades y posibilidades del sistema político, cuestión que los confronta con dilemas entre la acción con apego irrestricto al Estado de derecho, o la generación de redes de cooperación informal con la intención de establecer equilibrios que posibiliten el desarrollo del sistema democrático. Esto lleva directamente a la expresión disfuncional de las instituciones informales.

La actuación oculta de los agentes los expone de continuo a la tentación de sucumbir a disposiciones instintivas de agresión. Debido a que lo informal cubre un amplio campo oculto que se engrana a lo opaco y difuso - propios de las instituciones informales-, en el ámbito público puede derivar en corrupción, personalismo y diversas expresiones de lo cuasilegal o antilegal, como el clientelismo, el caciquismo, las redes de complicidad, todo lo que se podría resumir como instituciones informales que rivalizan con las formales, o las suplantan.

En el proceso político se manifiestan vacíos legales, contratos no oficiales y demás conformidades de los individuos que conducen al establecimiento de sistemas de relaciones simbólicas tipificadas recíprocamente, estableciéndose un escenario de posibilidades que es vivido por los individuos como si tuviera realidad propia. Quizás lo que más influye en la conducta de los individuos es que siguen las reglas de costumbre según la forma en que internalizan la autoridad, aunque también afectados por las circunstancias o contingencias, si la suerte les sonríe o la desgracia los golpea.

Las disposiciones instintuales del hombre son el origen primitivo de los sistemas de relaciones simbólicas. Esto permite comprender las formas en que se internaliza la norma y, por tanto, la orientación de los individuos a integrarse en redes de cooperación o someterse a las disposiciones instintivas de agresión. Pero lo real también origina restricciones que se viven como información incompleta y la imposibilidad de contratos perfectos, lo que permite la actuación de una pluralidad de poderes que en la interacción establecen acuerdos tácitos, preceptos, valores compartidos o tipificaciones recíprocas de acciones habitualizadas, todo lo que se condensaría en la categoría convenciones.

La fortaleza de las instituciones informales es definible según el carácter de las funciones que comportan. Para que lo informal adquiera el rango de institución deberá cumplir cuatro criterios, reformulados a partir de Hodgson (2006): 1) el grado en que otorgan estabilidad al comportamiento; 2) la medida en la que restringen el comportamiento de los actores; 3) la imprevisibilidad del cambio debido a su independencia de la voluntad de los agentes, 4) el grado en que facilitan la cooperación. En consecuencia, es factible afirmar 
que una institución informal es débil o no adquiere el rango de institución en la medida en que no cumple con dichos criterios.

De manera más amplia, aquí proponemos el abordaje de las instituciones informales por sus componentes funcionales, los disfuncionales, la fuente de la que surgen, los campos en los que se expresan, y las propiedades que las vuelven observables:

I. Componentes funcionales: 1) Formas de interiorización de la autoridad: implica inhibiciones instintivas y restricciones al comportamiento; 2) Tradiciones: establecen formas de cooperación y estructuras de credibilidad; 3) Pautas regularizadas: permiten la rutinización de prácticas y otorgan estabilidad al comportamiento, y 4) Intersubjetividad: implica relaciones simbólicas y significaciones imaginarias sancionadas socialmente, que las dotan de resistencia al cambio y plasticidad.

II. Componentes disfuncionales: 1) Campo difuso de la acción: se sostienen en las interacciones no reguladas explícitamente dando lugar a la acción social en la opacidad y lo oculto o inescrutable; 2) Acceso continuo a recursos del poder: la regularidad de los mismos individuos en el ejercicio de poderes tiende a desinhibir instintos primitivos; 3) Contingencias imprevistas: la imposibilidad de regulación u observación de toda acción disfuncional, 4) Transgresión de la autoridad: faltas en la interiorización de la norma refuerzan conductas egoístas en detrimento de la comunidad.

III.Fuentes de la institucionalidad informal: 1) La fuente primigenia es el proceso cultural; 2) la fuente derivada es la complejidad de la vida en comunidades de gran extensión, la modernidad que lleva al establecimiento de instrumentos racionales de coordinación, pero permanecen mecanismos tradicionales sostenidos por disposiciones o significaciones imaginarias.

IV.Arenas de expresión de lo informal: 1) El proceso político, 2) el proceso social y 3) el proceso económico.

V. Propiedades observables: las formas en que se relaciona con la ley, que pueden ser: 1) no oficial, 2) extraoficial, 3) antioficial y 4) metaoficial.

\section{Conclusión: a manera de sumario}

El artículo planteó una investigación teórica orientada a identificar los componentes de un posible discurso institucionalista informal. Se previó que la literatura existente no había precisado con sistematización los componentes 
de la categoría institución informal, y se buscó el argumento subyacente en la literatura sobre las instituciones informales

Se ha encontrado que los estudiosos empíricos de las instituciones informales utilizan de forma equívoca el concepto de institución informal, con referentes de índole disímil y, en algunos casos, heterogéneos, de manera que la noción connota lo que no es formal, aun cuando no atienda a la regularidad de prácticas.

Las denotaciones más exactas son lexicográficas, las que se distancian de referentes precisos, con lo que se evidencia la falta de una lista de cuestiones a las que aplique la noción, esto es, el campo de referentes incluidos en la categoría institución informal. De igual modo, se suelen desatender las formas de la relación entre lo formal y lo informal: cómo lo no formal se apega, relaciona, distancia o socava lo formal.

Con la guía de la investigación teórica en tres disciplinas de las ciencias sociales, y buscando rescatar ejes articuladores en los estudios empíricos contemporáneos, se ha intentado aquí recuperar las propiedades observables de las instituciones informales y reducir su equivocidad e indeterminación (Sartori, 2012). Así, la matriz conceptual de la tabla 1 da cuenta de las fuentes más relevantes, mediante el enlace del pensamiento de autores clásicos y contemporáneos con ejes temáticos. Esto permitió concluir, a partir de elementos significativos identificados en la literatura, con una propuesta de los factores o categorías principales para el análisis de las instituciones informales. Es importante agregar que esta propuesta conceptual juega ciertas veces a modo de hallazgos que, sumados a los aportes de estudiosos como Hodgson, Prats Cabrera y O’Donnell, amplían el horizonte de la línea de investigación.

Los resultados sugieren que un trabajo centrado sólo en los teóricos sociales permite la comprensión de la lógica institucional informal, pero el análisis de trabajos empíricos arroja que no parecen nutrirse de aquella teorización para dar forma a un discurso institucional informal cohesionado por categorías compartidas.

Aquí se ha explorado en los límites del concepto, ahora falta la investigación sobre las definiciones, membresía, o identificación de casos que encuadran en las delimitaciones propuestas (si bien quedan insinuadas en el artículo). Como desafío a la trascendencia de atender la parte informal de las instituciones, se ha decidido hablar de un institucionalismo informal. Aun cuando no se pueda decir lo mismo del surgimiento de una literatura enfocada en este campo de conocimiento, sí se ha planteado la existencia de una rica pero dispersa literatura, en diversas disciplinas, que contiene un implícito enfoque institucionalista informal. 


\section{Referencias}

Acemoglu, D., \& Robinson, J. A. (2013). Por qué fracasan los paises. México: Paidós.

Aguilar Villanueva, L. F. (2014). Las dimensiones y los niveles de gobernanza. Cuadernos de Gobierno y Administración Pública, 1(1), 11-36.

Aguilar Villanueva, L. F. (2013). Gobierno y administración pública. México: FCE/Conaculta.

Barrero Escobar, F. A. (2014). Instituciones formales e informales en la selección de candidatos en el ámbito subnacional colombiano. Elecciones 2011. Análisis Politico, 27(80).

Benton, A. L. (2007). The Strategic Struggle for Patronage - Political Careers, State Largesse, and Factionalism in Latin American Parties. Journal of Theoretical Politics, 19(1), 55-82. doi: $10.1177 / 0951629807071019$

Berger, P., \& Luckmann, T. ([1968] 2001). La construcción social de la realidad (S. Zuleta, Trad.). Buenos Aires: Amorrortu.

Berger, P., \& Pullberg, S. (1965). Reification and the Sociological Critique of Consciousness. History and Theory, 4(2), 196-211.

Castoriadis, C. (2013). La institución imaginaria de la sociedad. México: Tusquets.

Devine, F. (1997). Los métodos cualitativos. En D. Marsh \& G. Stoker (Eds.), Teoría y métodos de la ciencia poítica (pp. 145-159). Madrid: Alianza Editorial.

Erdmann, G., \& Engel, U. (2006). Neopatrimonialism Revisited-Beyond a Catch-All Concept. German Institute of Global and Area Studies. Recuperado de http://www.giga-hamburg .de/workingpapers

Freidenberg, F. \& Levitsky, S. (2007). Organización informal de los partidos en América Latina. Desarrollo Económico, 46(184), 539-568.

Freidenberg, F. \& Levitsky, S. (2006). Informal Institutions and Party Organizations in Latin America. En G. Helmke \& S. Levitsky (Eds.), Informal Institutions and Democracy Lessons from Latin America (pp.178-197). Baltimore : Johns Hopkins University Press.

Freud, S. (2003). El malestar en la cultura (L. López-Ballesteros, Trad.). Obras completas. Tomo 3 (1916-1938). Buenos Aires: El Ateneo.

Geddes, B. (1994). Politician's Dilemma: Building State Capacity in Latin America. Berkeley: University of California Press. 
Harris, M. (1998). La antropología y el estudio de la cultura. Genes, evolución y cultura. Antropología Cultural (pp. 13-65). Madrid: Alianza Editorial.

Helmke, G., \& Levitsky, S. (Eds.) (2006). Informal Institutions and Democracy: Lessons from Latin America. Baltimore: Johns Hopkins University Press.

Helmke, G., \& Levitsky, S. (2004). Informal Institutions and Comparative Politics: A research agenda. Perspectives on Politics, 2(4), 725-740.

Helpman, E. (2004). El misterio del crecimiento económico. España: Antoni Bosch Editor.

Henry, S., \& Sills, S. (2006) Informal economic activity: Early thinking, conceptual shifts, continuing patterns and persistent issues - a Michigan study. Crime, Law and Social Change, 45(4), 263-284.

Herskovits, M. J. ([1948] 1984). El hombre y sus obras. México: FCE.

High, C., Pelling, M. \& Nemes, G. (2005). Understanding informal institutions: Networks and communities in rural development.Transition in Agriculture, Agricultural Economics in Transition II. Budapest, Hungary, Institute of Economics, Hungarian Academy of Sciences. Recuperado de http://oro.open.ac.uk/2683/1/understanding_High2005e.pdf

Hilgers, T. (2007). Clientelism in the Party of the Democratic Revolution: Continuity and Change in Mexican Politics. Tesis doctoral, York University, Canada. Recuperado de http://search .proquest.com/docview/304787191

Hodgson, G. M. (2006). What Are Institutions?. Journal of Economic Issues, XL(1).

Hodgson, G. M. (1998, marzo). The Approach of Institutional Economics. Journal of Economic Literature, XXXVI, 166-192.

Johansson, K. M. \& Raunio, T. (2005). Regulating Europarties: Cross-Party Coalitions Capitalizing on Incomplete Contracts. Party Politics, 11(5), 515-534. doi: 10.1177/1354068805054978

Johnston, M. (2005). Syndromes of Corruption: Wealth, Power, and Democracy. Cambridge: Cambridge University Press.

Knight, A. \& Pansters, W. G. (2005). Caciquismo in Twentieth-Century Mexico. Institute for the Study of the Americas.

Leiras, M. (2004). ¿De qué hablamos cuando hablamos de instituciones informales? En A. Fernández (Ed.). Estudios de política comparada (pp. 65-92). Rosario: Universidad Nacional de Rosario. 
Liebert, S. (2007). Interaction of formal and informal institutions: The Case of Low-Wage Labor Migration from Kyrgystan to the United States. Tesis doctoral, The American University. District of Columbia. Recuperado de http://search.proquest.com/docview/304894026

MacCormick, N. (1998). Norms, Institutions, and Institutional Facts. Law and Philosophy, 17(3), 301-345.

Macharia, L. N. (2007). Clientelism, Competition and Corruption: Informal Institutions and Telecommunications Reform in Kenya, J.S.D., Stanford University, California. Recuperado de http://search.proquest.com/docview/304810904

Malinowski, B. ([1948]1976). Una teoría cientifica de la cultura, y otros ensayos (A. R. Cortázar, Trad.). Buenos Aires: Editorial Sudamericana.

March, J. G. \& Olsen, J. P. (1984). The New Institutionalism: Organizational Factors in Political Life. The American Political Science Review, 78(3), 734-749. doi: 10.2307/1961840

Mariscal, N. (2003). Teorías políticas de la integración europea. Madrid: Tecnos.

Martínez González, V. H. (2005). Fisiones y fusiones, divorcios y reconciliaciones: la dirigencia del Partido de la Revolución Democrática (PRD) 1989-2004. México: Flacso México/Plaza y Valdés.

Melucci, A. (1999). Democracia de la complejidad. Acción colectiva, vida cotidiana y democracia (pp. 161-198). México: El Colegio de México.

Middlebrook, K. J. (2009). Caciquismo and Democracy: Mexico and Beyond. Bulletin of Latin American Research, 28(3), 411-427. doi: 10.1111/j.1470-9856.2009.00308.x

Morgan, A. L. (1998). Corruption: Causes, Consequences and Policy Implications: A Literature Review. Working Paper Series, (Working Paper 9), recuperado de http://www.asiafoundation.org/pdf/wp9.pdf

Murdock, G. P. (1997). Cultura y Sociedad. 24 Ensayos (M. Caso, Trad.). México: FCE.

Navarrete U., C. A., \& Dolores Bautista, J. (2014). Caciquismo en Atlapexco, municipio de la Huasteca Hidalguense. Revista de El Colegio de San Luis, (8), 12-37.

North, D. C. (1993). Instituciones, cambio institucional y desempeño económico. México: FCE.

O’Donnell, G. (1996). Otra institucionalización. Política y Gobierno, 3(2), 219-244.

O’Donnell, G. (1994). Delegative Democracy. Journal of Democracy, 5(1), 55-69.

C. A. Navarrete Ulloa | Institucionalismo informal: tras las huellas de un discurso institucionalista informal Perfiles Latinoamericanos, 24(47) | FLACso México | pp. 283-306 | DoI: 10.18504/pl2447-003-2016 
Park, H. W., Thelwall, M. \& Kluver, R. (2005). Political Hyperlinking in South Korea: Technical Indicators of Ideology and Content. Sociological Research Online, 10(3), 19.

Patalano, R. (2007). Imagination and society. The Affective Side of Institutions. Constitutional Political Economy, 18(4), 223-241.

Peltier, J.-P. (2007). State Legitimacy in Sub-Saharan Africa, Ph.D., Michigan State University, Michigan. Recuperado de http://search.proquest.com/docview/304850423

Prats Cabrera, J. O. (2008). La búsqueda de las instituciones. Una teoría del desarrollo desde la informalidad. Recuperado de http://www.cidob.org

Reed, S. R. (1996). Political Corruption in Japan. International Social Science Journal, 48, 395-405.

Sartori, G. (2012). Cómo hacer ciencia politica (M. Á. Ruiz de Azúa, Trad.). Taurus.

Schutz, A. (1973). El mundo de la vida cotidiana y la actitud natural. Las estructuras del mundo de la vida (pp. 25-40). Buenos Aires: Amorrortu Editores.

Stacey, J. A. (2007). When agents defy principals: The impact of informal inter-organizational dynamics in the European Union, Ph.D., Columbia University, New York. Recuperado de http://search.proquest.com/docview/304863958

Suárez Relinque, C., Del Moral Arroyo, G. \& González Fernández, M. T. (2013). Consejos prácticos para escribir un artículo cualitativo publicable en Psicología. Psychosocial Intervention, 22(01), 71-79. doi:10.5093/in2013a9

Schutz, A. \& Luckmann, T. ([1973] 2001). Las estructuras del mundo de la vida. Buenos Aires: Amorrortu.

Van Biezen, I. \& Kopecky, P. (2007). The State and the Parties: Public Funding, Public Regulation and Rent-Seeking in Contemporary Democracies. Party Politics, 13(2), 235-254. doi: $10.1177 / 1354068807073875$

Recibido el 24 de julio de 2013. Aceptado el 12 de julio de 2015. 